\title{
Study of Driving Behavior in Ilioupolis, Athens According to the Environmental Affordances Theory
}

\author{
Efthimios Bakogiannis \\ Transportation Engineer \& Urban Planner, Ph.D., \\ Sustainable Mobility Unit- Department of Geography \& Regional Planning, \\ National Technical University of Athens \\ Charalampos Kyriakidis \\ Ph.D. Candidate, Urban \& Regional Planner, Transportation Engineer, \\ Sustainable Mobility Unit- Department of Geography \& Regional Planning, \\ National Technical University of Athens
}

\section{Abstract}

The urban space is characterized by specific qualities that may contribute to, or mitigate the social life. These qualities were described by James Gibson as "environmental affordances". But beyond social life, such environmental affordances can affect other human behaviors, such as driving behavior. Such an approach can be particularly useful, since the objective in most European cities is to regain the social character of roads and streets and thus to reduce the speeds on the roads and the number of cars. Through this research, conclusions can be drawn related to road elements that contribute to the development of high traffic speeds to prevent their use during urban planning while encouraging the use of other qualities that will support the maintenance of low speeds of cars. In the light of the above, the specific research focuses on a neighborhood of the southern suburbs of Athens, Ilioupolsi. Through observations and an electronic survey, conclusions are drawn on the behavior of drivers in Ilioupolis. Finally, an attempt is made to generalize the effects of the specific physical characteristics in order to optimize the design of cities where the roads will be social spaces in addition to vehicle traffic channels.

Keywords: environmental affordances, road design, driving behaviour, Ilioupolis, Athens.

\section{Introduction}

Roads are an important part of open public urban spaces in cities (Jacobs, 1961; Dumbaugh, 2005; Ghahramanpouri, et.al., 2012; Lamit, et.al., 2013; Mehta, 2013; Mahdzar, et.al., 2015; Shao, et.al., 2016), worldwide. According to Vlastos and Tsorou 
(2006), the streets are the most important places where pedestrians operate and are thus more perceived as social sites than as building and functional elements of cities. Jacobs (1961) and Malone (2002) agree to that view and argue that streets are the social settings where human personality and society are reflected. It is no coincidence that a series of studies (Jacobs, 1961; Carmona, et.al., 2003; Mehta, 2009; Mehta, 2013; Ghel, 2010; Ghahramanpouri, et.al., 2012) support the multidimensional role of roads (political, cultural, religious, psychological and symbolic), in the context of social life. For this reason, an understanding of the parameters that influence human behavior has also been the subject of research for space designers and environmental psychologists. The latter, in fact, have formulated a set of theories that justify the emergence of specific behaviors.

In this work, the use of such a theoretical approach is used not for the study of social behavior, but for the understanding of driving behavior. Earlier studies conducted at the Sustainable Mobility Unit, NTUA, found a relative incompatibility between understanding a road as a social site and its function as a motorized traffic channel. The speeds developed seem to be a parameter that negatively affects the sense of safe pedestrian traffic while making communication between them difficult. Thus, the following questions arise: What parameters affect the movement of vehicles at high speeds within cities? Are these parameters detrimental to the movement and concentration of pedestrians on the streets?

The above queries are attempted to be answered through this research. The issue is examined in the light of the environmental affordances theory in a particular neighborhood of Athens located in the southern suburbs called Ilioupolis. Two methodological tools, observation and questionnaire survey, are used in order for the issues studied to be explored and a holistic approach of environmental affordances is presented. Finally, the resulting conclusions are generalizations regarding the possible correlation between driving behavior and the shape of the road space. These conclusions can be useful in case studies of road section regeneration, in order to motivate citizens to make more use of roads as concentration and social gathering areas, enhancing the sense of community.

\section{Theory of Environmental Afordances}

This research lies within the scientific area of environmental psychology that, from the 2nd half of the 20th century (Clayton and Saunders, 2012; Cassidy, 1997), studies the relationship of the environment and human behaviour (Scholz, 2011). Thus, over the last decades, a number of studies have turned its interest in understanding people's behavior, utilizing different theoretical approaches. According to Moser and Uzzell (2003), the major theories are grouped into three groups of theoretical thinking: determinism, interactionism and transactionism. The approach of environmental affordances falls within the transactionistic theories. 
Under this theory, any human behaviour is related to the possibilities offered by the space on every user, each time (Warren, 1984; Greeno, 1994). According to Mehta (2013), environmental affordances are not treated as elements that are characterized by "obligatory" to the users of the space qualities but as elements of the environment that make it capable of developing some experience as well as experiencing some aesthetic experience. Althouth, the various features of the site can support or constrain behaviours, this does not mean that these behaviors will definitely take place (Gibson, 1979). Indeed, environmental affordances are a "real chance" for the event of an action (Tillas, et.al., 2017). Characteristic is the example that is demonstrated by Gaver (1996), who expects that the number of moving individuals on space located at a higher altitude level from another is less because of the height difference.

Although several groupings of environmental affordances have been formulated (Fallah and Fallah, 2015), the most frequent categorization is that based on the "benefit of the user" criterion and distinguishes the affordances into positive and negative affordances. Other categorizations can be made based on "actor's involvement" (potential or actualized affordances) or "perceiving acting agent" criteria (individual or shared affordances). These types of categorization were used in this specific research paper, which uses the affordances as a mean of understanding driving behavior.

\section{Methodology}

To answer the research questions, a particular area was selected as a case study. According to Jennings (2001), case study research is a kind of a primary research since it offers new information both qualitative and quantitative, in order to draw conclusions that will be useful in design projects of similar research theme (Kyriakidis, 2016; Bakogiannis, et.al., 2017). The characteristic that makes them a useful and reliable tool of research is that they are empirical studies of the phenomenon under the scope of real life, as Yin (1984) notes.

Ilioupolis was selected because it: (a) is characterized by an average degree of compactness (Kyriakidis and Iliadis, 2018), consisting a typical city case, (b) constitutes an autonomous non-center neighborhood within the metropolitan area of Athens, which is important since most researches on how a place can become socially more active concern the central districts rather than the neighborhoods (Mahmoudi Farahani, et.al ., 2015), (c) is located on the perimeter of the metropolitan area of Athens and is crossed by major motorways that operate as an extension of the regional ring (Attiki Odos) (d) is an area developed after urban planning and not in an anarchic way, as several areas in Greece, (e) has a wide variety in the characteristics of the roads, as there are many highways where high traffic loads are recorded, as well as local roads, (f) is among the municipalities that will develop the Sustainable Urban Mobility Plan (SUMP) and will therefore design and implement interventions that will affect mobility at municipal level.

Concerning the understanding of driving behavior in Ilioupolis, two methods were chosen: (a) Drive-by and walk-by observation; and (b) Questionnaire survey. The first 
method aimed at the recording of basic driver mobility choices, such as the approximate calculation of average speed, giving priority to pedestrians when they use zebracrossings for crossing the roads, the maintenance of priority in the nodes, parking in areas where parking is prohibited, the use of traffic lights, etc. The second method aimed at understanding the perception of drivers about how they are moving to Ilioupolis. Through the questionnaire survey, it is checked whether drivers understand the behavior they express; for example, understanding of the speeds they reach when they drive, understanding of the cases when they violate a signal, etc., as well as the attempt to understand the motivation for the expression of specific behavior. The survey was conducted between 8-22 June 2018, electronically. 91 people participated in the survey. They were informed via social media. In that way the random character of sample selection among residents or visitors of the city who have an account on a social media platform was ensured. Regarding the profile of the survey participants, the majority of participants are men (53.3\%), aged 25-35 (66.7\%), university graduates $(52.2 \%)$ driving a car or motorcycle $(91,1 \%) .56 .7 \%$ of the respondents declare residents of Ilioupolis, while the others visit the study area on a daily basis (45.7\%) or 3-5 times a week (30.4\%). It is worth noting that the majority of questions were closed-ended, since in open-ended research the open questions do not find the appropriate response from the respondents (De Bruijne and Wijnant, 2014; Zhou, et.al., 2017).

The results obtained from the field research were evaluated in the light of the literature on environmental affordances. A table was accrued, showing the affordances found in Ilioupolis and are classified according to the "benefit of the user" and perceiving acting agent" criteria.

\section{Case Study: The Municipality of Ilioupolis, Athens}

Ilioupolis is located in the southern part of the metropolitan area of Athens. Its population is 78,153 inhabitants and the population density is estimated at $13,175.8$ inhabitants $/ \mathrm{km}^{2}$. Indeed, it is characteristic that it consists a relatively compact municipality in its urban section (Kyriakidis and Iliadis, 2018), assessing a number of parameters, such as public transport coverage, the height of buildings and the surface of public and green spaces.

Although the balance of public spaces versus private ones is positive for public spaces, however, most of them are not attributed to the use of pedestrians but to the movement of motor vehicles. The city is crossed by highways and roads of large width with high traffic loads. On most of these roads, the speeds developed are above the permissible limit within urban areas. Indeed, $69 \%$ of the respondents said that the average speed of their vehicles in Ilioupolis is $40-60 \mathrm{~km} / \mathrm{h}$ when the permissible limit is $50 \mathrm{~km} / \mathrm{h} .4 .6 \%$ of the participants even underlined that their average speed in Ilioupolis is more than 60 $\mathrm{km} / \mathrm{h}$. As the main cause of high speed development, the large width of the roadway was considered the most important parameter (52.9\%), while the number of lanes and the existence of a separating island were two other features that favored this. As 
respondents are also pedestrians, when they were asked they think that cars are moving at high speeds on the main streets of the city, 78.9\% of respondents responded affirmatively. However, it is paradoxical that even from those who recognize that they have exceeded the speed limit (76\%), only the $46 \%$ believe that they exceed the boundary within an urban area.

These features are evident on roads such as Marinou Antypa Ave., Andrea Papandreou Ave. and Heroon Polytechniou Ave., which after Eleftheriou Venizelou Ave., an extension of Attiki Odos, are roads identified as roads where drivers develop high speeds. In fact, some intersections on the above roads were characterized by the participants in the questionnaire survey as dysfunctional. However, this parameter does not seem to affect the land values in the Municipality of Ilioupali, as the property rating index tend to be increased form the southeast to the northwest side of the municipality. It seems that wide-width roads and avenues -in which heavy traffic loads are recorded (General Study for Traffic Control and Parking Management in the Municipality of Ilioupolis, 2017)- are being evaluated in a positive way due to the fact that act like connecting axes with the center of Athens and the northern suburbs of the Athens metropolitan area. The question of the movement of the drivers at the junctions focused on the roundabouts that are numerous in Ilioupolis. The majority of survey respondents consider that they are largely served by the city's roundabouts (40.5\%). The same positive was their attitude towards the regulation of traffic with traffic lights, since most (70.6\%) do not consider that there are delays in the rotation of the movements and therefore do not feel that such a delay causes them to violate the red signal.

The survey also looked at the attitude of drivers towards pedestrians crossing the streets. Although the majority (35.8\%) of respondents uses the crossings during their crossing on the main streets of Ilioupolis when they move as pedestrians, only about $30 \%$ of the total assess the crossing of the central streets of Ilioupolis as comfortable. This may be due to the fact that crossings are also located and where there is no traffic light, resulting in a large number of drivers not stopping. Indeed, $50 \%$ of the respondents do not stop at the crossings when there is no traffic light.

The on-street parking was another phenomenon that was largely observed in Ilioupolis, as in many Greek cities (Vlastos and Chronopoulos, 2007; Kyriakidis and Bakogiannis, 2018). On both central and local roads, parking along the road and sometimes even on the sidewalk seemed to make it harder for pedestrians to move. However, only $25.2 \%$ of respondents consider parking to be one of the reasons that make it very difficult or too difficult for them to be pedestrians. This view is perhaps related to the satisfactory assessment of the pavements in terms of their width (39.7\%). This view relates, in particular, to the sidewalks of the main roads where the sidewalks are of sufficient width and the existence of additional pavement patch (area between the street line and the building one), that in several places is not delimited, creates the sense of even larger pavements. A similar situation prevails on some roads that have been restored and function as mild traffic roads. However, it has been found that there are many points in 
the city where the width of the sidewalks is too small, so it is not enough even for the safe movement of healthy people.

Regarding the issue of the protection of pedestrian traffic on the sidewalks, the attitude of residents and visitors was investigated for the use of equipment, such as the pillars, to restrict parking. $41.7 \%$ of respondents are taking such measures positively to make pedestrian movement easier and safer. This point of view is important because, recently, railings have been placed in order to release the pavements from parked cars. In addition to the portable obstacles, horizontal marking can also act as a deterrent to parking. Indeed, lining and using pictograms prevents drivers from parking at specific points. It is typical that $94 \%$ of respondents in the survey have never parked on a bicycle lane marked by road markings.

\begin{tabular}{|c|c|c|c|c|c|c|c|c|c|c|c|c|c|c|c|c|c|c|}
\hline & 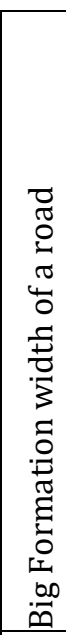 & 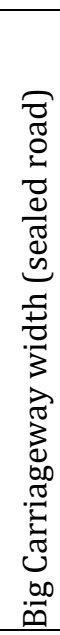 & 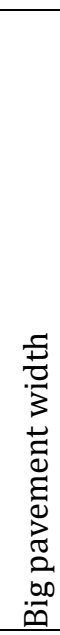 & $\frac{\vec{U}}{\tilde{n}}$ & 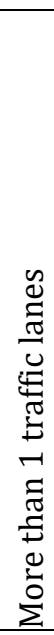 & $\begin{array}{l}5 \\
\frac{5}{5} \\
3 \\
0 \\
0 \\
\stackrel{0}{9} \\
.00 \\
.00\end{array}$ & 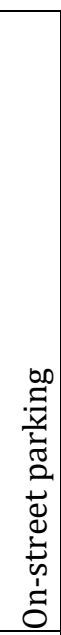 & 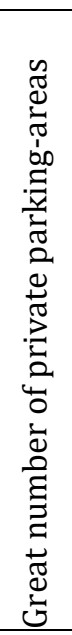 & 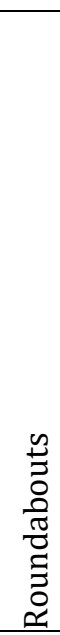 & 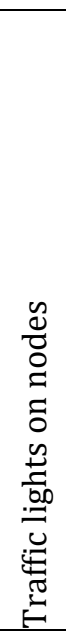 & 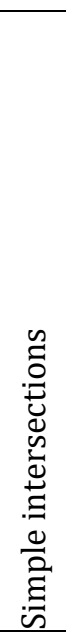 & 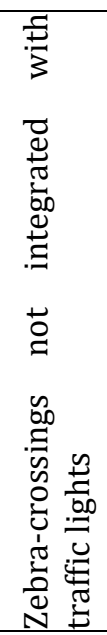 & 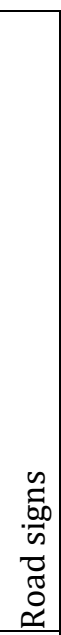 & 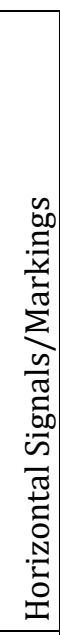 & 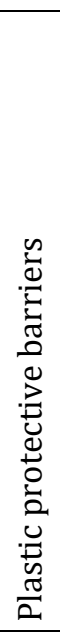 & 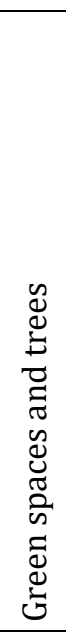 & 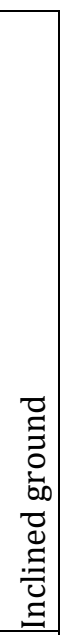 & 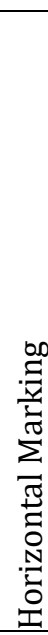 \\
\hline 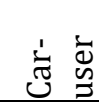 & $\mathrm{P}$ & $\mathrm{P}$ & $\begin{array}{l}\mathrm{P} \\
*\end{array}$ & $\mathrm{P}$ & $\mathrm{P}$ & $\mathrm{P}$ & $\begin{array}{l}\mathrm{N} \\
*\end{array}$ & $\mathrm{~N}$ & $\mathrm{P}$ & $\mathrm{P}$ & $\mathrm{N}$ & $\mathrm{N}$ & $\mathrm{P}$ & $\begin{array}{l}\mathrm{N} \\
*\end{array}$ & $\mathrm{~N}^{*}$ & $\mathrm{P}^{*}$ & $\mathrm{~N}$ & $\mathrm{~N}$ \\
\hline 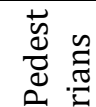 & $\begin{array}{l}\mathrm{P} \\
*\end{array}$ & $\mathrm{~N}$ & $\mathrm{P}$ & $\begin{array}{l}\mathrm{N} \\
*\end{array}$ & $\mathrm{~N}$ & $\mathrm{~N}$ & $\mathrm{~N}$ & $\mathrm{~N}$ & $\begin{array}{l}\mathrm{N} \\
*\end{array}$ & $\mathrm{P}$ & $\mathrm{N}^{*}$ & $\mathrm{P}$ & $\begin{array}{l}\mathrm{P} \\
*\end{array}$ & $\mathrm{P}$ & $\mathrm{P}$ & $\mathrm{P}$ & $\mathrm{N}$ & $\begin{array}{l}\mathrm{P} \\
*\end{array}$ \\
\hline \multicolumn{19}{|c|}{$\begin{array}{l}\mathrm{P}^{*} / \mathrm{N}^{*}: \text { potentially possitive or negative affordances. } \\
\text { It should be noted that some estimations are made by taking into account the functional } \\
\text { or social character of each affordance. }\end{array}$} \\
\hline
\end{tabular}

Table 1. Main environmental affordances in Ilioupolis, Athens, categorized according specific criteria. Source: Own Elaboration.

The above points were evaluated in the light of the literature for environmental affordances. Once identified, they are tabulated and presented in Table 1. It should be noted that the affordances presented in this table are an indicative list of the most important affordances for the whole municipality. A corresponding, more detailed 
record on a smaller scale (i.e. street or neighborhood scale) may bring to light other affordances not listed in Table 1.

The sum of the recorded affordances (17) were evaluated on the basis of the "benefit of the user" criterion for two categories of users (drivers and pedestrians) and categorized into positive and negative. However, some affordances are characterized as potentially positive or negative depending on the benefits to the user most likely to have. As depicted in Table 1, motor vehicle drivers tend to have more benefits from the existing planning in the municipality of Ilioupolis. $44.4 \%$ of the affordances were positive for the comfortable movement of vehicles, while $11.2 \%$ were potentially positive. For pedestrians, $33.3 \%$ of the affordances were positively evaluated and $16.6 \%$ potentially positive. Respectively, as negative affordances for vehicle traffic were evaluated the large number of private parking areas, simple intersections, zebra-crossings not integrated with traffic light and the inclined ground. The affordances in terms of pedestrian traffic characterized as negative were more.

The above confirm the fact that Ilioupolis is a neighborhood of Athens that is designed with an orientation that serves the most motor vehicles rather than the pedestrians, as most Greek cities (Vlastos and Perperidou, 2007). It is no coincidence that $50 \%$ of respondents to the questionnaire survey do not express a clear position on the question: "How safe do you feel as a pedestrian in Ilioupolis?" The recent regeneration of some road sections seems to be moving towards pedestrian protection. However, a single united planning is required to promote sustainable mobility throughout the municipality, through integrated strategies, ensuring both pedestrian safety and the limitation of the circulation of motor vehicles. The affordances presented in Table 1 can serve as indicators for progress in the area of sustainable mobility. Thus, the design goal should be to increase positive environmental affordances for pedestrians, even if this means limiting the comfort of vehicle traffic, at least on local roads.

Finally, it is worth noting that the increase of positive affordances for pedestrians is expected to have a positive impact on cyclists as well, since the physical characteristics of an area influencing the presence of pedestrians affect in a similar way, in the majority, the presence of cyclists as well. These characteristics include the width of the pavement, as there is no autonomous bicycle space, the degree of shading of the pavements, the urban green, the ease of crossing the roads, etc.

\section{Conclusions}

Streets are fundamental parts of cities and people's everyday life. Nevertheless, over the decades, large surfaces of them have been conceded to the use of cars. As a result, they function more as traffic channels than spaces of social interaction. This situation tends to be reversed through the implementation of SUMPs, based on the European Union's guidelines, to make roads safer for pedestrians and to regain their importance as social sites. To do this, a number of street interventions aim to modify some of their physical 
characteristics, assuming that they affect the choice of the means of moving by people as well as their behavior as drivers, cyclists or pedestrians.

These physical characteristics are called environmental affordances and were described in the context of homonymous theory, which falls within the field of environmental psychology. The affordances recorded in an area can be categorized in a number of ways: positive, negative, actualized or potential, affordances perceived by drivers or pedestrians.

The above theoretical approach has been applied in the case study examined in this research paper concerning the Municipality of Ilioupolis. Ilioupolis is a neighborhood in the southern part of the metropolitan area of Athens with large public areas. Although the degree of urban compactness for its urban segment is relatively high, however, a large part of its public spaces are the streets, thus limiting the sociability in its public spaces. The ratio between roads and public spaces for pedestrians has been the motivation for exploring driving behavior in Ilioupolis and the way it is influenced by the physical design of the area.

To investigate the issue, a questionnaire and walk-by and drive-by observation research was conducted to capture behaviors and investigate the cause of their expression. The research has shown that physical characteristics are related to driving behavior as well as pedestrian behavior. The conclusions that have emerged for Ilioupolis can, under certain conditions, be generalized for other Greek cities, as well, with corresponding characteristics. In summary, the key findings can be described as follows:

The large sealed road width contributes to the development of higher speeds than the permissible speed limit. Other parameters that affect high speed development are the number of lanes per direction and the existence of a separating islet between the traffic flows. In any case, the existence of an islet is legitimate, since its geometrical characteristics are such that do not discourage pedestrian movement and the safe crossing of the roads, since they consist urban areas. Regarding the width of the sealed road, it is legitimate to keep it in small widths within urban network to prevent high speeds. An alternative would be to use different asphalt material.

Roundabouts are rated more positively than negative. Negative evaluation of roundabouts occurs to a greater extent by pedestrians who do not have access to the central island area, even if there is a design that predicts their presence in it. In any case, the operation of roundabouts in Greek cities could be more efficient as long as there was a better education of drivers in terms of priority and the combination of different means such as roundabouts, traffic lights and vertical marking was prevented.

The adjustment of traffic into nodes with traffic lights against typical nodes (priority settings) is more efficient and safer. However, switching of traffic light signals should be tactical so as not to encourage drivers to violate light signals. 
On-street parking is a parameter that prevents pedestrian movement. However, its effects are smaller, as long as there are wide widths of sidewalks. Potentially negative may be the effects of the parking garage and for drivers since they have difficulty in parking and traffic on the road. Negative impacts on drivers also arise from the existence of a large number of private car parking areas, as they have difficulty in finding a car park.

Obstacle use can be a satisfactory method of limiting on-street parking and parking on the sidewalks. A large portion of the audience agrees with their use. An alternative could be to pinpoint and use pictograms for easy and cost-effective interventions, at least in a stage of public opinion adaptation for future permanent footpaths or regeneration of streets.

The above points summarize the findings of research on the psychology of drivers who move to an area with specific physical characteristics. It was found that there was a correlation between driving behavior and the existence of specific features, which, in theory, was more established for pedestrian behavior. Research may further specify the relationship between driving behavior and pedestrian traffic in the study area as well as focus more on the parameters that affect the use of the bicycle as a means of transport. Through such an integrated approach, important conclusions could be drawn that shape a set of policies that need to be taken into consideration when designing roads, which has been increasingly observed in Greek cities over the last few years due to the increased demand for SUMPs. Thus, because through such a behavioral research the psychology of behavior is being examined, it can be said with relative certainty that designs based on such policies are expected to have positive effects on the safety of citizens, the enhancement of the publicity of public spaces and the development of a strong community sense.

\section{References}

[1] Bakogiannis, E., Kyriakidis, C., Siti, M. and Eleftheriou, V. (2017). Four stories for sustainable mobility in Greece. Transportation Research Procedia, 24, 345-353.

[2] Carmona, M. Heath, T. Oc, T. and Tiesdell, S. (2003). Public Places - Urban Spaces: The Dimensions of Urban Design. London: Elsevier.

[3] Cassidy, T. (1997). Environmental Psychology: Behaviour and Experience in Context. Hove and New York: Psychology Press Ltd.

[4] Clayton, S. and Saunders, C. (2012). Introduction: Environmental and Conservation Psychology. In Clayton, S. (ed.). The Oxford Handbook of Environmental and Conservation Psychology. New York: Oxford University Press, 1-10.

[5] De Bruijne, M. and Wijnant, A., 2014.Improving response rates and questionnaire design for mobile web surveys. Public Opinion Quarterly, 78(4), 951-962. 
[6] Dumbaugh, E. (2005). Safe Streets, Livable Streets. Journal of the American Planning Association, 71(3), 283-300.

[7] Fallah, S.M. and Fallah, S.M. (2015). Identifying Environmental Affordance in Design Case Study: Kerman, Iran. Journal of Applied Environmental and Biological Sciences, 5(7S), 445-450.

[8] Gaver, W. (1996). Affordances for interaction: the social is material for design. Ecological Psychology, 8(2), 111-129.

[9] Gehl, J., 2006. Life between buildings: using public space. Translated from Danish by J. Koch. Washington, DC; London: Island Press.

[10] General Study for Traffic Control and Parking Management in the Municipality of Ilioupolis, 2017.

[11] Ghahramanpouri, A., Lamit, H and Sedaghatnia, S. (2012). Behavioural Observation of Human Stationary and Sustained Activities in Pedestrian Priority Streets of Johor Bahru. Journal of Construction in Developing Countries, 17(2), 105-116.

[12] Gibson, J. (1979). An Ecological Approach to Visual Perception. Boston, MA: Houghton Mifflin.

[13] Greeno, J. (1994). Gibson's affordances. Psychological Review, 101 (2), 336-342.

[14] Jacobs, J. (1961). The death and life of great American cities. New York: Vintage Books Editions.

[15] Jennings, G. (2001). Tourism Research. New Jersey: John Wiley and Sons.

[16] Kyriakidis, C. (2016). The function of urban public space in relation to local parameters: Comparative study between Larisa and Nottingham. Aeichoros, 24, 67-85.

[17] Kyriakidis, C. and Bakogiannis, E. (2018). How the physical characteristics may affect the social life of streets in Athens, Greece? European Journal of Social Sciences, Education and Research, 12(1), 15-23.

[18] Kyriakidis, C. and Iliadis, F. (2018). Compactness evaluation of the Athens metropolitan area. 11 th International Conference of the Hellenic Geographical Society. Laurio, Greece, 12-15 April 2018.

[19] Lamit, H., Ghahramanpouri, A. Sepideh Sedaghat N. (2013). A Behavioral Observation of Street Liveliness in Meldrum Walk, Johor Bahru of Malaysia. International Transaction Journal of Engineering, Management, \& Applied Sciences \& Technologies, 4(1), 3-14. 
[20] Mahdzar, S.S.B.S., Baghi, M.H. and Baghi, M.H. (2015). Influence of Physical Conditions on the Outdoor Activities at the Street Level: A Case Study of Wong Ah Fook Street in Johor Bahru, Malaysia. International Journal of Scientific and Technology Research, 4(9), 1-7.

[21] Mahmoudi Farhani, L., Lozanovska, M. And Soltani, A. (2015). The social life of commerical streets. 8th Making Cities Liveable Conference. 6-7 July 2015, Mebourne, Australia.

[22] Malone, K. (2002). Street life: youth, culture and competing uses of public space. Environment and Urbanization, 14(2), 157-168.

[23] Mehta, V. (2009). Look closely and you will see, listen carefully and you will hear: Urban design and social interaction on streets. Journal of Urban Design, 14 (1), 29-64.

[24] Mehta, V. (2013). The street: A quintessential social public space. London and New York (NY): Routledge.

[25] Moser, G. and Uzzell, D. (2003). Environmental Psychology. In: Million, T. and Lerner, M. (eds.). Handbook of Psychology - Volume 5: Personality and Social Psychology. New Jersey: John Wiley \& Sons, Inc., 419-446.

[26] Scholz, R. (2011). Environmental Literacy in Science and Society: From knowledge to decisions. Cambridge: Cambridge University Press.

[27] Shao, L., Mittelstadt, S., Goldblatt, R., Omer, I., Bak, P. and Schreck, T., 2016. Street Explorer: Visual Exploration of Feature-based Patterns in Urban Street Networks. 11 th Joint Conference on Computer Vision, Imaging and Computer Graphics Theory and Applications. Rome, Italy. 27-29 February 2016.

[28] Tillas, A., Vosgerau, G., Seuchter, T. and Zipoli Caiani, S. (2017). Can Affordances Explain Behavior? Review of Philosophy and Psychology, pp. 1-21.

[29] Vlastos, Th. and Chronopoulos, G. (2007). Obstacles to walking. Quantitative valuation in the case of Athens. Law and environment, 39(1), 38-44.

[30] Vlastos, Th. and Perperidou, D.G. (2007). Planning for walking. Technical Chronicle Scientific Journal of TCG, I(3) 2007, 33-43.

[31] Vlastos, Th. and Tsorou, F. (2006). Influencing factors of pedestrians' behavior in a junction. The case study of Katehaki-Mesogeion Streets in Athens. Technical Chronicle Scientific Journal of TCG, I(3) 2006, 21-33.

[32] Warren, W. (1984). Perceiving affordances: visual guidance of stair climbing. Journal of experimental psychology: Human perception and performance,10(5), 683-703. 
[33] Yin, R.K. (1984). Applications of case study research (Applied Social Research Methods). California: Sage Publications.

[34] Zhou, R., Wang, X., Zhang, L. and Guo, H. (2017). Who tends to answer openended questions in an e-service survey? The contribution of closed-ended answers. Behaviour and Indormation Technology, 36(5), 1-11. 